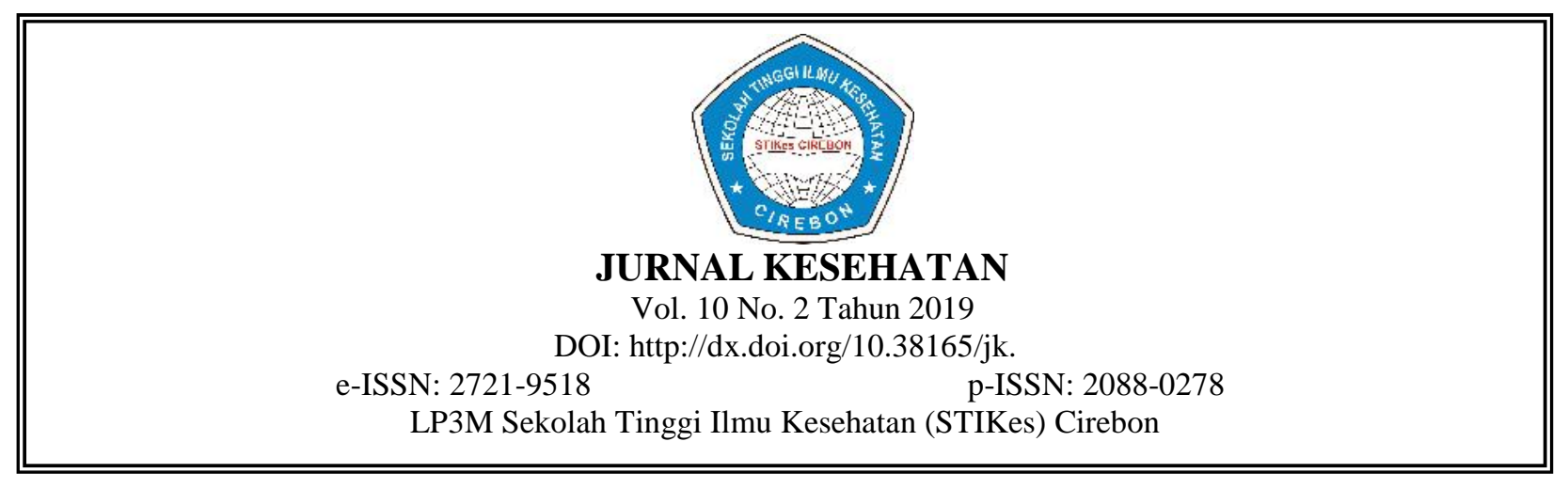

\title{
KEPUASAN PELANGGAN INTERNAL TERHADAP PELAYANAN LABORATORIUM KLINIK
}

\author{
Destu Satya Widyaningsih* \\ Program Studi D3 Analis Kesehatan Manggala Yogyakarta \\ destu.satya@gmail.com \\ I Wayan Kurniawan** \\ Program Studi D3 Analis Kesehatan Manggala Yogyakarta
}

\begin{abstract}
Abstrak
Instalasi laboratorium klinik merupakan salah satu penunjang pelayanan kesehatan di RS PKU Muhammadiyah Gamping Sleman yang mengedepankan pelayanan prima kepada pelanggan eksternal atau internal. Pelayanan kepada pelanggan eksternal lebih sering diperhatikan dan dilakukan penelitian dibandingkan pelayanan kepada pelanggan internal yang masih sering diabaikan serta berdasarkan hasil observasi pada tanggal 24 Januari 2019 di laboratorium klinik RS PKU Muhammadiyah Gamping Sleman pengukuran kepuasan pelanggan internal belum pernah dilakukan penelitian. Tujuan penelitian ini adalah untuk mengetahui kepuasan pelanggan internal terhadap pelayanan laboratorium di RS PKU Muhammadiyah Gamping Sleman. Jenis penelitian ini menggunakan desain penelitian deskriptif kualitatif menggunakan pendekatan cross sectional. Populasi pada penelitian ini adalah dokter yang bertugas di RS PKU Muhammadiyah Gamping Sleman yaitu sebanyak 49 dokter. Teknik pengambilan sampel pada penelitian adalah dengan Accidental sampling sebanyak 20 dokter yang bertugas di RS PKU Muhammadiyah Sleman. Analisa data dengan menggunakan rumus yang tercantum dalam pedoman umum penyusunan indeks kepuasan masyarakat unit pelayanan instansi pemerintah. Hasil penelitian didapatkan bahwa Kepuasan Pelanggan Internal Terhadap Pelayanan di Laboratorium Klinik RS PKU Muhammadiyah Gamping Sleman mendapatkan hasil penilaian sebesar 98.5 dengan kategori A yang mengandung arti sangat memuaskan.
\end{abstract}

Kata Kunci: Kepuasan, pelanggan internal, layanan laboratorium

\begin{abstract}
The clinical laboratory unit belongs to one of the supporting health services at the PKU Muhammadiyah Gamping Hospital which aims to provide excellent service to both external and internal customers. External customer satisfaction is more commonly evaluated compared to that of internal customers. According to the preliminary observatory study, internal customer satisfaction has never been evaluated previously at the PKU Muhammadiyah Gamping Hospital. Current study aims to evaluate internal customer satisfactory rate with clinical laboratory services at the PKU Muhammadiyah Gamping Hospital. The descriptive study was conducted by using cross sectional design in 49 medical doctors of PKU Muhammadiyah Gamping Hospital. Accidental sampling method was used in determining the 20 final respondents. Data analysis was performed according to the standard index on measurements of satisfactory rate in government institutions. The study demonstrated high satisfactory rate of 98.5, of which belonged to very satisfied under category A.
\end{abstract}

Keywords: satisfaction, internal customer, laboratory service 


\section{PENDAHULUAN}

Instalasi laboratorium klinik merupakan salah satu penunjang pelayanan kesehatan di RS PKU Muhammadiyah Gamping Sleman yang mengedepankan pelayanan prima kepada pelanggan eksternal atau internal. Pelayanan kepada pelanggan eksternal lebih sering diperhatikan dan dilakukan penelitian dibandingkan pelayanan kepada pelanggan internal yang masih sering diabaikan serta Berdasarkan hasil observasi pada tanggal 24 Januari 2019 di laboratorium klinik RS PKU Muhammadiyah Gamping Sleman pengukuran kepuasan pelanggan internal belum pernah dilakukan penelitian. Maka dari itu perlu dilakukan penelitian untuk mengetahui kepuasan pelanggan internal terhadap pelayanan laboratorium di RS PKU Muhammadiyah Gamping Sleman.

Konsep penelitian tentang kepuasan pelanggan yang saat ini yang dikembangkan oleh para ahli masih populer adalah konsep lima dimensi utama pengukuran kepuasan, ${ }^{1}$ yaitu: Kelima dimensi mutu tersebut, meliputi 1) Tampilan fisik (tangible) yaitu meliputi fasilitas fisik, perlengkapan, pegawai, dan sarana komunikasi; 2) Kehandalan (realibility), yaitu kemampunan memberikan pelayanan yang dijanjikan dengan segara, akurat, dan memuaskan;3) Daya tanggap (responsiveness), yaitu keinginan para staf untuk membantu para pelanggan dan memberikan pelayanan dengan tanggap; 4) Jaminan (assurance), yaitu mencangkup pengetahuan, kemampuan, kesopanan, dapat dipercaya, bebas dari bahaya, dan resiko atau keragu-raguan; 5) Empati (emphaty), yaitu kemudahan dalam melakukan hubungan komunikasi yang baik, perhatian pribadi, dan memahami kebutuhan pelanggan.

Pelanggan adalah orang-orang yang membeli atau menggunakan produk maupun jasa pelayanan maka disebut dengan pelanggan (customer), pelanggan pelayanan kesehatan secara umum adalah masyarakat individu, kelompok atau institusi penggunaan jasa pelayanan kesehatan yang membutuhkan pelayanan kesehatan atau yang mempunyai potensi menggunakan jasa pelayanan kesehatan, maka pelanggan dapat dibedakan ke dalam dua jenis pelanggan yaitu pelanggan internal dan pelanggan eksternal. ${ }^{2}$

Pelanggan internal adalah semua orang yang bekerja dalam organisasi layanan kesehatan yang mempunyai kepentingan tertentu serta mempunyai akses untuk memberikan layanan kesehatan, pelanggan internal sangat penting karena harus dapat bekerja sama dalam menghasilkan pelayanan kesehatan yang bermutu untuk mencapai standar pelayanan laboratorium yang baik. Pada penelitian ini yang dimaksud pelanggan internal meliputi staf adminitrasi medis, dokter serta petugas kesehatan lainya. ${ }^{3}$

Pelanggan eksternal Adalah orang yang berada diluar organisasi layanan kesehatan yang memperoleh pelayanan kesehatan yang dihasilkan oleh organisasi layanan kesehatan, Pelanggan eksternal adalah pemakai akhir dari produk jasa kesehatan yang sering disebut sebagai pelanggan nyata pelanggan eksternal ini meliputin pasien, keluarga pasien, pengunjung, pemerintah, perusahaan asuransi kesehatan, masyarakat umum, lembaga swadaya masyarakat dan lain-lain. ${ }^{4}$ Tujuan dari penelitian ini adalah untuk mengetahui kepuasan pelanggan internal terhadap pelayanan laboratorium di RS PKU Muhammadiyah Gamping Sleman.

\section{METODE PENELITIAN}

Jenis penelitian ini menggunakan desain penelitian deskriptif kuantitatif menggunakan pendekatan cross sectional untuk mengetahui tingkat kepuasan pelanggan internal terhadap pelayanan Laboratorium Klinik Di RS PKU Muhammadiyah Gamping Sleman. Populasi pada penelitian ini adalah dokter yang bertugas di RS PKU Muhamadiyah Gamping Sleman yaitu sebanyak 49 dokter. Teknik pengambilan sampel pada penelitian adalah dengan Accidental sampling yaitu pemilihan sampel secara khusus atau kebetulan ada dan tersedia di suatu tempat serta sesuai dengan konteks penelitian. Diperoleh sampel sebanyak 20 dokter yang bertugas di RS PKU Muhamadiyah Sleman. ${ }^{5}$

Data primer menjadi data yang dipilih dalam mengumpulkan data karena data primer dapat diperoleh melalui pengumpulan kuesioner dari responden setelah mendapatkan pelayanan Laboratorium Klinik Di RS PKU Muhammadiyah Gamping Sleman. Analisa data dengan 
menggunakan rumus yang tercantum dalam pedoman umum penyusunan indeks kepuasan masyarakat unit pelayanan instansi pemerintah, ${ }^{6}$ dengan rumus sebagai berikut:

$$
\underset{\text { Tertimbang }}{\text { Bobot Nilai Rata-rata }}=\frac{\text { Jumlah Bobot }}{\text { Jumlah Unsur }}=1=0,1
$$

Nilai tingkat kepuasan dihitung dengan menggunanakan "nilai rata-rata tertimbang" masing masing unsur pelayanan. Dalam perhitungan tingkat kepuasan pelanggan internal terhaap 10 unsur pertanyaan mengenai pelayanan yang dikaji, setiap unsur pertanyaan mengenai pelayanan memiliki penimbang yang sama. Untuk memperoleh nilai tingkat kepuasan digunakan pendekatan nilai ratarata tertimbang dengan rumus sebagai berikut:

\section{Tingkat Kepuasan $=$ Total dari nilai persepsi per unsur $\mathrm{x}$ Nilai Penimbang Total unsur yang terisi}

Untuk Memudahkan Interpretasi terhadap nilai kepuasan pelanggan maka digunakan nilai yaitu antara 25-100 dan hasil tersebut diatas dikonveksikan dengan nilai tengah 50, dengan rumus sebagai berikut:

\section{TINGKAT KEPUASAN X 50}

Mengingat unit pelayanan mempunyai karakteristik yang berbeda-beda, maka setiap unit pelayanan dimungkinkan untuk:

1. Menambahkan unsur yang dianggap relevan.

2. Meberikan bobot yang berbeda terhadap 10 unsur unsur yang dominan dalam dalam unit pelayanan, dengan catatan jumlah bobot seluruh unsur tetap 1 .

Tabel 1. Interval Nilai Kepuasan

\begin{tabular}{ccccc}
\hline Nilai Persepsi & $\begin{array}{c}\text { Nilai Inerval } \\
\text { Kepuasan }\end{array}$ & $\begin{array}{c}\text { Nilai Interval } \\
\text { Konversi } \\
\text { Kepuasan }\end{array}$ & Mutu & $\begin{array}{c}\text { Kinerja Unit } \\
\text { Pelayanan }\end{array}$ \\
\hline 1 & $0,00-0,50$ & $25-43,75$ & D & Tidak Baik \\
2 & $0,51-1,00$ & $43,76-62,50$ & C & Kurang Baik \\
3 & $1,01-1,50$ & $62,51-81,25$ & B & Baik \\
4 & $1,51-2,00$ & $81,26-100$ & A & Sangat Baik \\
\hline
\end{tabular}

\section{HASIL PENELITIAN}

Hasil penelitian ini disajikan dalam tabel 2 di bawah ini:

\begin{tabular}{|c|c|c|c|c|c|c|c|}
\hline \multirow{2}{*}{ No } & \multirow{2}{*}{ Indikator } & \multirow{2}{*}{ Sub Indikator } & \multicolumn{2}{|c|}{ Puas } & \multicolumn{2}{|c|}{ Tidak Puas } & \multirow{2}{*}{$\begin{array}{l}\text { Nilai } \\
\text { Unsur }\end{array}$} \\
\hline & & & $\mathrm{Jml}$ & $\%$ & Jml & $\%$ & \\
\hline 1 & 2 & 3 & 4 & 5 & 6 & 7 & 8 \\
\hline 1. & Kehandalan & Akurasi dan presisi hasil pemeriksaan & 20 & 100 & - & - & 2,0 \\
\hline 2. & Daya tanggap & $\begin{array}{l}\text { Kecepatan dan ketepatan melayani test } \\
\text { laboratorium } \\
\text { Pengetahuan dan kemampuan Petugas }\end{array}$ & 20 & 100 & - & - & 2,0 \\
\hline 3 & jaminan & $\begin{array}{l}\text { Terhadap Pemeriksaan yang sedang } \\
\text { dikerjakan }\end{array}$ & 20 & 100 & - & - & 2,0 \\
\hline 4. & Empati & penyerahaan hasil pemerikasan & 18 & 90 & 2 & 10 & 1,8 \\
\hline
\end{tabular}

Tabel 2. Hasil nilai rata-rata dan prosentase dari masing-masing indikator laboratorium 


\begin{tabular}{rlllllcc}
$\mathbf{1}$ & \multicolumn{1}{c}{$\mathbf{2}$} & \multicolumn{1}{c}{$\mathbf{3}$} & $\mathbf{4}$ & $\mathbf{5}$ & $\mathbf{6}$ & $\mathbf{7}$ & $\mathbf{8}$ \\
5. & Bukti Fisik & ketersediaan alat laboratorium dan & 19 & 95 & 1 & 5 & 1,9 \\
metode pemerikasaan & $\begin{array}{l}\text { Petugas } \\
\text { laboratorium }\end{array}$ & $\begin{array}{l}\text { Pelayanan, Kesiapan petugas } \\
\text { laboratorium }\end{array}$ & 20 & 100 & - & - & 2,0 \\
7. & $\begin{array}{l}\text { Petugas } \\
\text { laboratorium }\end{array}$ & Keterampilan petugas laboratorium & 20 & 100 & - & - & 2,0 \\
8. & $\begin{array}{l}\text { Pelayanan } \\
\text { pemeriksaan }\end{array}$ & $\begin{array}{l}\text { Permintaan pemeriksaan rentang waktu } \\
\text { 24 jam }\end{array}$ & 20 & 100 & - & - & 2,0 \\
9. & $\begin{array}{l}\text { Pelayanan } \\
\text { pemeriksaan }\end{array}$ & Permintaan cito & 20 & 100 & - & - & 2,0 \\
10. & $\begin{array}{l}\text { Laporan hasil } \\
\text { pememriksaan }\end{array}$ & $\begin{array}{l}\text { Tanggung jawab terhadap hasil } \\
\text { pemeriksaan }\end{array}$ & 20 & 100 & - & - & 2,0 \\
\hline
\end{tabular}

Untuk mengetahui nilai tingkat kepuasan terhadap pelayanan laboratorium maka dihitung dengan cara sebagai berikut:

$$
\begin{gathered}
(2,0 \times 0,1)+(2,0 \times 0,1)+(2,0 \times 0,1)+(1,8 \times 0,1)+(1,9 \times 0,1)+(2,0 \times 0,1)+(2,0 \times 0,1)+(2,0 \times \\
0,1)+(2,0 \times 0,1)+(2,0 \times 0,1)+(2,0 \times 0,1)+(2,0 \times 0,1)=1,97
\end{gathered}
$$

Dengan demikian nilai tingkat kepuasan terhadap pelayanan laboratorium dapat disimpulkan sebagai berikut:

1. Nilai tingkat kepuasan $=$ Nilai tingkat kepuasan $\times$ Nilai tengah $=1.97 \times 50=\mathbf{9 8 . 5}$

2. Mutu pelayanan A

3. Kinerja pelayanan laboratorium Sangat Baik

\section{PEMBAHASAN}

Berdasarkan seluruh data hasil penelitian pada penelitian Tingkat Kepuasan Pelanggan Internal Terhadap Pelayanan Di RS PKU Muhmammadiyah Gamping Sleman sudah sesuai dengan teori pengukuran kepuasan bahwa kepuasan pasien akan tercapai bila diperoleh hasil pelayanan yang optimal dan melampaui harapan setiap pasien, serta ada perhatian terhadap keluhan, kondisi lingkungan fisik dan tanggap kepada kebutuhan pasien sehingga akan tercapai keseimbangan yang baik. Konsep penelitian tentang kepuasan pelanggan yang saat ini yang dikembangkan oleh para ahli masih populer adalah konsep lima dimensi utama pengukuran kepuasan. ${ }^{1}$

Pada dimensi empati menunjukkan angka kepuasan $90 \%$ dengan nilai unsur 1,8. Hal ini tidak sesuai dengan teori yang menyatakan bahwa kesesuaian waktu pemeriksaan dan penyerahan hasil pemeriksaan oleh petugas laboratorium harus mampu menempatkan diri dalam memberian perhatian penuh kepada pelanggan, paham dan mengerti akan kebutuhan pelanggan, perhatian terhadap kepentingan pelanggan dan juga kesesuaian waktu pelayanan dengan kebutuhan pelanggan. ${ }^{1}$ Terdapat $10 \%$ responden yang tidak puas dalam mendapatkan pelayanan empati pada proses pelayanan laboratorium.

Ketidakpuasan ditemukan juga pada indikator Bukti Fisik dengan nilai prosentasi sebesar 95\% dan nilai rata-rata unsur 1,9. Terdapat 5\% responden yang menyatakan tidak puas dalam mendapatkan pelayanan laboratorium berupa bukti fisik. Hal ini tidak sesuai dengan teori yang menyatakan bahwa ketersediaan alat laboratorium dan metode pemeriksaan berkaitan dengan ketersediaan sarana dan prasarana termasuk alat yang siap pakai serta penampilan dari petugas kesehatan yang menyenangkan dan akan mempengaruhi tingkat loyalitas pelanggan. ${ }^{1}$

Berdasarkan seluruh data hasil penelitain tentang Kepuasan Pelanggan Internal Terhadap Pelayanan Di RS PKU Muhmammadiyah Gamping Sleman, sudah sesuai dengan teori pengukuran kepuasan. Hasil penilaian tentang kepuasan pelanggan internal tehadap pelayanan laboratorium yang diukur berdasarkan pedoman umum penyusunan indeks kepuasan masyarakat unit pelayanan instansi pemerintah diperoleh penilaian 98.5 dengan kategori A yang mengandung arti sangat memuaskan. 


\section{SIMPULAN}

Berdasarkan penelitian ini maka dapat diambil kesimpulan bahwa penilaian tentang Kepuasan Pelanggan Internal Terhadap Pelayanan Di RS PKU Muhmammadiyah Gamping Sleman, yang diukur berdasarkan pedoman umum penyusunan indeks kepuasan masyarakat unit pelayanan instansi pemerintah diperoleh penilaian 98.5 dengan kategori A yang mengandung arti sangat memuaskan.

\section{SARAN}

Hasil penelitian ini dapat digunakan sebagai masukkan bagi pihak rumah sakit untuk meningkatan kualitas pelayanan yang ada dilaboratorium untuk pelanggan internal, terutama pada indikator dimensi empati dan bukti fisiknya.

\section{DAFTAR PUSTAKA}

1. Bustami, M.S. Penjaminan mutu pelayanan kesehatan dan akseptabilitasnya. Padang: Erlangga; 2011.

2. Muninjaya, A.A. Gede. Mananjemen mutu pelayanan kesehatan Ed. 2. Jakarta: Buku kedokteran EGC; 2014

3. Pohan, I. S. Jaminan mutu layanan kesehtan dasar-dasar pengertian dan penerapan. Jakarta: Buku kedokteran EGC; 2006

4. Sundari, M. N. Kualitas pelayanan kesehatan Di RSUP Sanglah Denpasar dari perspektif pelanggan internal dan eksternal. Tesis. Bali: Program Pasca sarjana Universitas Udayana Denpasar; 2014.

5. Notoatmodjo, S. Metodologi penelitian kesehatan. Jakarta: Rineka Cipta; 2010.

6. Kepmenpan RI. Nomor: KEP/25/M.PAN/2/2004. Tentang Pedoman Umum Peyusunan Indeks Kepuasan Masyarakat Unit Pelayanan Instansi Pemerintahan. Jakarta: Kepmenpan RI; 2004. 